\title{
Determination of iodine value of palm oil by differential scanning calorimetry
}

\begin{abstract}
Iodine value (IV) is used as a parameter in process control as well as a quality parameter in traded palm oil products. IV measures the number of double bonds in the molecular structure of an oil. To form a double bond, carbon requires more energy $(615 \mathrm{~kJ} / \mathrm{mol})$ than to form a single bond $(350 \mathrm{~kJ} / \mathrm{mol})$. Therefore, the thermal behavior of an oil could reflect its iodine value. This study was conducted to demonstrate the use of a differential scanning calorimeter (DSC) to determine the IV of palm oil and its products as an attempt to reduce the use of chemicals in the analysis. The DSC thermograms of palm oil showed a clear separation of the substances that have low melting points (low-T), consisting of triunsaturated, monosaturated and disaturated triglycerides, from the high ones (high-T), consisting of trisaturated triglycerides. Regression analysis showed that the peak characteristics, namely, area and height of the low-T group and height of the high-T group in the heating thermogram and also the height of the high-T group in the cooling thermogram, can predict the IV of palm oil with R 2 higher than 0.99. This study concludes that DSC can be used to determine the IV of palm oil and its products.
\end{abstract}

Keyword: DSC; HPLC; Iodine value; Palm oil; Thermal behavior; Triglyceride 